\title{
The Research on Civil Passenger Service Strategy based on Internet Thinking
}

\author{
Shujia Wan \\ Tourism collage, Northwest Normal University, Lanzhou Gansu 730070, China \\ paperiset@163.com
}

Keywords: Service marketing, civil aviation service, 7P.

\begin{abstract}
As the quick development of the national aviation market, competition among major market players has been severe in recent years, even though it seems to have been in a smooth status. Hubei Airline was established later than other local regional players; therefore, in order to incessantly enlarge the customer pool, to enhance the loyalty of the customers and to improve the core competitiveness, Airline has carried out Internet Thinking. However, there is still a long way to go to compete with the giant airlines, particularly in the perspectives of target positioning, customer segmentation, service experiencing of membership, service value driving and so on. This paper studies the fields of customer segmentation, target market selection and positioning via analyzing the existing problems and the causes of the Internet Thinking on the basis of the views of service marketing. Based on the Internet Thinking, this paper finally proposes reasonable solutions concluding the fields of regional differentiation, concentrated marketing strategy, 7P portfolio, customer-faced marketing strategy and feasible safeguard.
\end{abstract}

\section{Introduction}

Due to the low degree of differentiation between airlines in our country, the domestic aviation market competition is strong, as the strict limitation on the aviation industry in our state, the competition is relative inequality in domestic market, and most companies do not have enough marketing strategies to competing with others [1]. Aviation industry development in our country at present stage is rapid, with the improved people's living consumption, tourism booming, our country is in a golden period of the development in aviation industry.

Thanks to the development of more than one decade, the customer pool has been tremendously enlarged. Air transport industry is a high-tech, high-cost, high-risk industry has been development rapidly in China in the past decade. Currently, the service of the domestic airlines is similar difference. Most of the domestic airlines is lack of core competitive power [2]. The size of the NF airlines is relatively small, the company is young, its market positioning and marketing strategy has certain flexibility, and it has certain complementary on the marketing strategy by the support of the holding company. As the civil aviation market of competition becoming more fiercer, the airlines need to make-strengths to implement more advanced and competitive service marketing strategy, in the compression space and create higher profits need to weigh and choose between highly service quality and brand effect, so as to win the market and consumers with differentiation strategy.

But NF Airlines have some problems, such as irrational company structure, the lack of market awareness changes in and many other issues. Therefore, in the new competitive environment, with the structure of consumers, NF airlines should reconfirmed mainstream passengers to target markets [3]. Then develop practical, effective marketing strategies. Enhancing core competitiveness has become the important issues for NF airline. It is of great realistic significance for NF airlines to implementation the strategic objectives of "mainstream passenger recognition, the most valuable, most profitable, world competitiveness company".

First this paper introduces the theory of marketing services, the characteristics of Air transport service marketing to provide a theoretical basis for the analysis. Then this paper analysis the internal and external market environment of NF airlines with modern marketing theory based on the status of 
air transport market and NF airlines. In the third part of this papers, the component of mainstream passengers is reconfirmed that mainstream passengers not only business passengers but also travelers. In the fifth part of this paper, the analysis is based on SWOT theory to discuss the strength, weakness, opportunity, threat of NF airlines. In the sixth part of this papers, after market segmentation, the recommendation of market targeting is the mainstream passengers. Then the targeting market is positioned. At the last of this paper, it provides the Service Marketing Strategy and some helpful suggestion of 7Ps.

\section{Civil Passenger Service Strategy based on Internet Thinking}

With the rapid development of the global air transport industry and the continuous improvement of information technology level, more and more airlines provide passengers with cabin Internet access service, the technical service allows passengers to enjoy Internet service at an altitude of my diameter, which not only adds a little fun to the journey, but also provides business passengers with an office and communication convenience specially, and providing airline cabin Internet access service has become an important means to seize the passengers resources [4]. In China, only a handful of airlines can provide this service on several flights, isolated information resources phenomenon of flying aircrafts within Chinese territory still exist, the technology development in China is lagging behind. Aviation passenger volume growth chart is shown in Fig. 1.

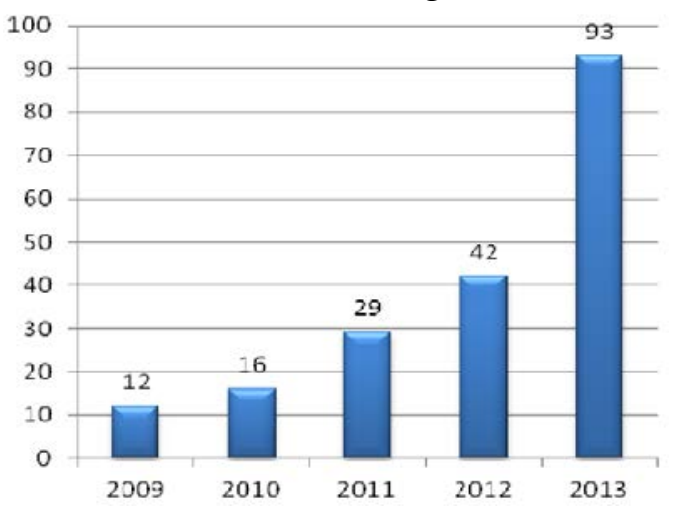

Fig. 1 Aviation passenger volume growth chart

Organization of the Text. This article intends to draw lessons from frontier service marketing theory, combine the reality of China's civil aviation market, to explore suitable for NF airlines development way of service marketing, the competition in the market, passenger demand, fully analyze the industry environment, using the advanced concept of service marketing and management theory, combining the theory and case, analysis of the defects in the current NF company's service marketing, and provide the basis for the future related to raise the capacity of the concept, build the NF airlines good customer satisfaction and loyalty, and expand the brand influence, thus to further improve the operation ability and competitiveness. The number of civil aviation aircraft in 2006-2014 is shown in Fig. 2.

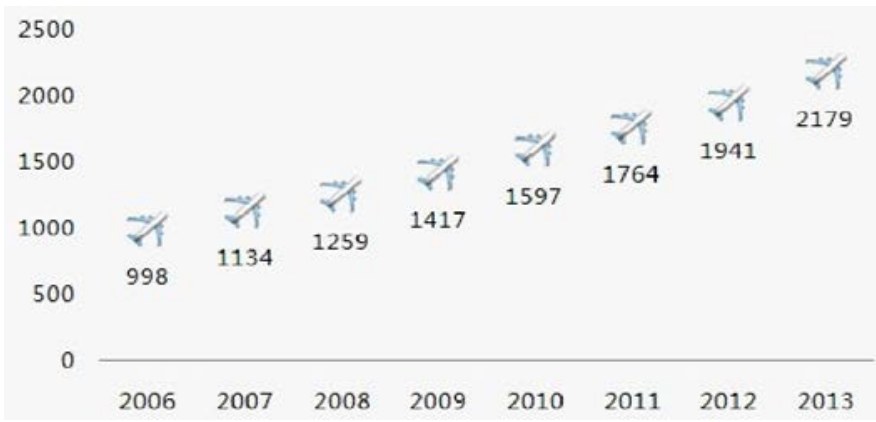

Fig. 2 2006-2014 number of civil aviation aircraft

Airline Cabin Internet Access Technology. Through research the patent development of airline cabin Internet access technology, analysis the high quality patents in this field, find the key technology solutions, focus on the enterprises which have strong research and innovation capacity in 
this field, that can provide valuable competitive intelligence for our Chinese enterprises and related research institutions, build upon international advanced technology, solve the key technical problem, develop intellectual property rights owned by itself, provide a convenient and fast Internet service for our airline passengers as soon as possible, and make our related enterprises to occupy a space in the fierce global competition.

In this paper, we made airline cabin Internet access technology as the research object, analysis based on patent data and made daren't innovations index as the main data source. Use patent information analysis, social network analysis, and weighted method of simple additively and SWOT analysis as main methods [5]. This paper does the research on airline cabin Internet access technology development based on patent information analysis.

Firstly, this paper research on airline cabin Internet access technology development in the world. Retrieve related patent of airline cabin Internet access technology from daren't innovations index, predict the technology life cycle by using the technology life cycle theory and Logistic model. The patent of this technology developed since 1982 has experienced a technology germination stage and a technology growth stage, and is currently in the technology mature stage. By the selection of evaluation index of patent quality, and given the weight, according to the predicted results of the patent technology life cycle, evaluate the quality of patents applying in germination stage, growth stage and mature stage respectively, find out the high quality patents in each stage, and analysis the two technical solution of airline cabin Internet access technology including satellite-based technology and the technology based on ground base station. Use the patent information analysis method; evaluate the research and innovation capacities of major participating institutions in the airline cabin Internet access technology from multiple perspectives. Analysis found that aircraft manufacturers represented by Boeing, airline cabin Internet access facilitators represented by Airline, aviation electronic equipment manufacturers and onboard entertainment service providers represented by Panasonic in this field.

Secondly, this paper research on airline cabin Internet access technology development in China. We analyze respectively from the time series of patent application, the type and legal status of patents, the patentee distribution, the key research direction of patents and other aspects. Analysis found that China started late, the patents quantity is small and quality is not optimistic in this field. At the same time, there is a lack of leading participants. Research and development have yet been on scale. The overall development situation is not so satisfactory:

Lastly, based on the above analysis of patent information, we analyze the advantages, weaknesses, opportunities and threats of the airline cabin Internet access technology development in China. Then establish a SWOT model, find problems existing in the current development of airline cabin Internet access technology in China through the SWOT analysis, and give corresponding solutions.

\section{P Service Marketing Combination}

In today's Internet information age, by product, price, channel, and promotion of four elements of traditional marketing mix (4 p), have a difficult to solve the problems in the service marketing of. Service is an activity and a process, which makes people have a inevitable impact on quality of service, interaction between staff and customers become the indispensable steps in the process of service production. At the same time, the service of intangible and imperceptible, make customers feel more risky when consumer services, customer looking for tangible evidence to help them identify services. Therefore, personnel, tangible demonstration and process become together with the traditional "4P" service marketing combination, namely the "7P".

Products: is no longer tangible items, but the service sector, service quality, service level, service brand, service guarantee and after-sale service and other factors.

Price: not only are important factors related to customer ability, is also a significant basis for customers judge the quality of service. Price factors to consider include: price, discount, discount and commission, payment terms and credit. 
Channel: in service activities, the location of the service site, storage and transportation accessibility and cover the elements, such as the geographical scope of the in service marketing channel strategy is very important. Channel type also has a great influence on the efficiency of service delivery.

Promotion: this includes advertising, personal selling, sales promotion and other promotional methods of all kinds of marketing communication. In the service marketing promotion is paid more attention to the different customer different message, through the promotion to provide customers with personalized service and information.

Personnel: including all the services of the participants, such as service providing, customers and other staff in the service environment.

Process: refers to the service delivery process and operating system. Service process is a key link in the process of consumers' cognition and perception to service level, which is the process of evaluating the enterprise service and product quality.

Presentation: including the environment, equipment and substantive clues, visible display good can make the service more convenient, can improve the service quality and production efficiency.

\section{Summary}

In the digital, networked, information age, first-class airline not only a first-class facilities, but also have first-class software services. The level of service quality, reflects the airline's level of development and overall strength, determines the airline passengers and other customers of the appeal. Means of innovative services, improve services, and strive to provide perfect service for visitors to experience, have become the international aviation industry trends. With the development of the world's airlines, the improvement of road and rail network, increasing competition for the airline customer base. Fight for passengers, it is necessary to improve the quality of service quality, enhance the level of passenger service. This paper studies the fields of customer segmentation, target market selection and positioning via analyzing the existing problems and the causes of the Internet Thinking on the basis of the views of service marketing. Based on the Internet Thinking, this paper finally proposes reasonable solutions concluding the fields of regional differentiation, concentrated marketing strategy, 7P portfolio, customer-faced marketing strategy and feasible safeguard.

\section{References}

[1] A. Jahn, M. Holzbock. Evolution of communications for personal and multimedia service. IEEE Communications Magezine, 2013 (41): 25-36.

[2] E.Sakhaee, A. Jamalipour. The Global In-Flight Internet. IEEE Journal on Selected Area in Communications, 2015 (9):1748-1757.

[3] Yang, S. H., Dai, C., and Knott, R. Remote maintenance of control system performance over the Internet. Control Engineering Practice, 2012 (5):533-544.

[4] Cheng A C, Chen C Y. The technology forcasting of new material: The example of nanosized ceramic powders. Romanian Journal of Economic Forecasting, 2008 (5): 88-110.

[5] Guan J C, Gao X. Exploring the h-index at patent level. Journal of the American for Information Science and Technology, 2010 59(13): 1-6. 